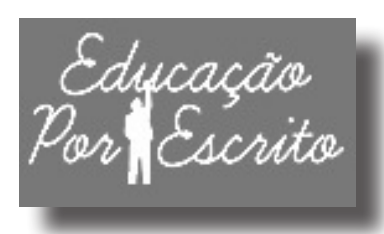

RESENHA http://revistaseletronicas.pucrs.br/ojs/index.php/porescrito

doi)" http://dx.doi.org/10.15448/2179-8435.2017.2.27491

\title{
Competências ou saberes?
}

Competences or knowledge?

Marina Camargo Mincato ${ }^{a}$

\section{RESENHA DE:}

\section{Editores}

Maria Inês Côrte Vitoria PUCRS, RS, Brasil Pricila Kohls dos Santos PUCRS, RS, Brasil

\section{Equipe Editorial}

Rosa Maria Rigo

PUCRS, RS, Brasil

PERRENOUD, Philippe. Desenvolver competências ou ensinar saberes? A escola que prepara para a vida. Porto Alegre: Penso, 2013. 224 p.

$\mathrm{P}$ hilippe Perrenoud, suíço nascido em Bienne, em 1955, formou-se em Ciências Sociais e é considerado um renomado pensador da Educação, com suas produções permeando o campo das competências dos alunos. Dedica seus estudos às práticas pedagógicas, com ênfase no currículo escolar, embora não tenha formação em Pedagogia. Doutor em Sociologia e Antropologia, atua nas faculdades de Psicologia e de Ciências da Educação da Universidade de Genebra, e no Brasil se destaca pelas bases inovadoras acerca da formação de professores e políticas educacionais.

Autor do livro Desenvolver competências ou ensinar saberes?: a escola que prepara para a vida, Perrenoud propõe uma reflexão sobre o papel da escola no desenvolvimento de competências. Lança alguns questionamentos fundamentais a respeito dos saberes ensinados na escola, indagando se são de fato os mais relevantes para levar o educando a compreender e atuar no mundo. E vai além, convidando o leitor a se posicionar quanto a questões bastante pontuais, como, por exemplo, se a escola cumpre sua missão, e pormenorizando, a rever qual é, de fato, a missão da escola.

A sociedade moderna acumula impactantes transformações em todos seus setores, desde a tecnologia e os processos de globalização até as relações individuais e coletivas. Essa realidade

\footnotetext{
a Mestranda em Educação, na linha de pesquisa Formação de Professores, Teorias e Práticas Educativas do Centro Universitário Unilasalle.
} 
remodela o mercado de trabalho e os desafios de adaptação, qualificação e inovação nesse meio. Nesse cenário, Perrenoud apresenta o desafio da escola em preparar esse jovem para a vida e para o trabalho, elencando a revisão do currículo sobrecarregado como foco de estudo, sem enaltecer ou fragilizar qualquer vertente, e analisando o desenvolvimento de competências na escola ou o ensino de saberes.

Partindo da premissa que o homem se constrói a partir das relações que estabelece com o meio, o autor não caracteriza as competências como um caminho, mas sim como uma adaptação do ser humano ao seu viver. Assim, cada indivíduo, com suas particularidades, desenvolve competências para solucionar questões corriqueiras do cotidiano. Competências essas que ainda possuem um conceito vago, gerando uma fragilidade que ameaça as possíveis reformas no ensino. Essas fragilidades envolvem justamente a missão da escola. No capítulo Introdução geral: é possível desenvolver competências sem questionar os conhecimentos?, Perrenoud aborda os conhecimentos escolares questionando se os saberes ensinados na escola são pertinentes para entender e agir no mundo atual, preparando o aluno para a vida, ou se somente embasam estudos superiores.

$\mathrm{O}$ autor antecipa que, de modo geral, dá-se enfoque às competências pela preocupação que a escola tem em preparar para a vida. E aqui claramente posiciona-se ao afirmar que "a vida é a esfera da ação, em oposição àquela dos exames escolares" (p.11) O modelo de escola atual busca preparar o aluno para o acesso ao ensino superior, treinando-o para testes e exames nacionais com identidades bastante nítidas. Desenvolvem-se, então, competências que se unem a habilidades específicas de saberes trabalhados na teoria que nem sempre vão ser relacionados à vida real. Para que haja uma significação naquilo que se aprende na escola, Perrenoud ressalta que esta tem condições de fornecer os alicerces para múltiplos conhecimentos que sejam utilizados em situações cotidianas para a vida dos educandos, e não simplesmente apresentar conteúdos a serem aprofundados na universidade. Mas, afinal, que conteúdos são esses a serem ensinados? Respondendo à própria indagação, o autor atesta que tal resposta deriva de um modelo particular de sociedade em consonância com a visão do humano que a integra.

Estruturada em três partes, a primeira sessão Competência do que estamos falando?, organizada em cinco capítulos, busca analisar a inconsistente conceitualização de competências, indicando como as reformas por um ensino baseado no desenvolvimento de competências prepara mais firmemente o jovem para a vida. Destaca ainda a relação entre conhecimentos e competências, diferenciando-as de habilidades.

No primeiro capítulo, intitulado $\mathrm{O}$ fascício pelas competências, o autor busca justificar a razão pela qual o mercado de trabalho evidencia as competências na parte de gestão organizacional, enquanto a escola as utiliza para reformas de currículo. Isto se deve principalmente ao fato da quebra de paradigmas dominantes, com a emergência de um novo ideal que rompe o pensamento tradicional, o qual se satisfazia com o que era ofertado: a evolução da sociedade. Em contrapartida, as instituições modernas aspiram ao progresso contínuo, produto de uma competitividade 
notória. Nas palavras de Perrenoud, "são cada vez mais raros os setores nos quais é possível sobreviver sem aprender" (p. 31) Questões que englobem os princípios de cidadania e democracia, sustentabilidade, convivência e diversidade cultural são tópicas e implicam o desenvolvimento de novas competências. Quanto ao currículo, este deve ser um instrumento orientado que designe as competências, mobilizando múltiplos recursos cognitivos no enfrentamento e solução desses conflitos.

O segundo capítulo, Partir preferencialmente da vida das pessoas, em vez de ter os programas como ponto de partida, intensifica as ideias traçadas previamente sobre reformas curriculares, incluindo um diferente ponto de vista. Muitas vezes, a escola pensa em adotar uma abordagem por competências a partir de uma lacuna que se verifica entre teoria vista na escola e aplicação prática do conteúdo na vida real.

Logo, surge uma nova questão: na formação profissional, pode-se ter maior nitidez na escolha desses conteúdos, uma vez que se tem um recorte das habilidades e competências que o profissional deve ser capaz de executar. Por outro lado, na educação básica, não há previsibilidade clara de quais conteúdos a criança fará uso com o passar do tempo. Atenta-se para a tendência que se tem a cair nos reducionismos, restringindo o espaço escolar àquilo que se imagina ser útil. Para tal, a escola tenta manter seus currículos calcados na neutralidade, preservando os conteúdos que vêm sendo ensinados ao longo dos anos, em sua quase totalidade.

Como fechamento do capítulo, Perrenoud constata que para se pensar nas competências faz-se necessário pensar nas situações, o que suscita muitas dúvidas, começando pelo conceito de competência. Competências e situações, título do capítulo seguinte, aborda justamente essa articulação, trazendo diferentes autores com seus conceitos para competência. Todas elas convergem a um mesmo elemento: uma competência é fruto de uma aprendizagem a partir da ação humana, sendo totalmente observável. Porém, trata-se de um resultado que pode ser inferior ou superior ao que se estipula. Portanto, não seria justo considerar um único resultado para se emitir uma avaliação: diferentes achados devem ser analisados e contrastados para gerar um parecer final com precisão.

Novamente, surge o conflito entre conceitualização de competência. O quarto capítulo já sinaliza no próprio título o enfoque dado: Confusões conceituais. Aqui, Perrenoud retoma os conceitos que diferentes autores trazem sobre competência, sinalizando suas citações que envolvem a ideia de "família" de situações. Essas compõem um contexto. É nesse contexto que condições e estratégias de aprendizagem são criadas a fim de preparar os alunos atentando para o currículo, criticado por dar as costas aos conhecimentos, consequentemente à cultura.

Todo aluno deve ser visto na sua individualidade e na sua pluralidade. Cada educando que constitui uma sala de aula tem seu conhecimento prévio de mundo, suas vivências, suas crenças e costumes, portanto, sua cultura. Trata-se de seres culturais, que devem ser concebidos em sua totalidade. E as competências fazem parte da cultura. Muitas destas começam fora do ambiente escolar. Dessa maneira, a escola não é o único espaço 
formador para o desenvolvimento de competências: este, por si só, não basta. Perrenoud adverte que se deve intervir com inteligência, sem desvalorizar os conhecimentos que esses alunos trazem em nome do conhecimento científico.

No último capítulo dessa primeira parte, Linhas de fuga: dois cenários possíveis, Perrenoud resgata a incompatibilidade de conceitos para competência, acrescentando que essas confusões estimulam e, ao mesmo tempo, mascaram as possibilidades de relação entre as competências e as famílias de relação. Para tal, o autor sustenta que, antes de se repensar as atividades pedagógicas enquanto educadores, deve-se ter plena noção das próprias competências individuais, mapeando novas possibilidades e limitações nesse percurso.

O sexto capítulo da obra, primeiro dessa segunda sessão, discute as Disciplinas consagradas e fundamentadas em um campo do saber. Trata-se da obrigatoriedade de algumas disciplinas no currículo, propondo o debate de quais conteúdos preparam para a vida e quais preparam para o ingresso em uma universidade. A questão cultural desempenha forte impacto aqui, uma vez que influencia os sistemas educacionais, bem como a época em que se vive. Contudo, Perrenoud destaca que, mesmo que um conteúdo esteja elencado a ser trabalhado dentro de uma determinada disciplina, nem sempre é efetivamente ensinado. Assim, o autor resgata sua proposta: verificar como os conteúdos do currículo formal se relacionam com a aplicação prática na vida.

A temática do capítulo 6 é revisitada no capítulo seguinte, As educações, no qual se distingue o objetivo de uma disciplina confrontada com uma educação. Enquanto a primeira se organiza em torno de um corpus de conhecimentos e conteúdos, a última dá enfoque ao desenvolvimento do aluno no que diz respeito a valores, atitudes, comportamentos e competências. Assim como há discussão dos elementos consagrados no currículo, Perrenoud trata no capítulo 8 das disciplinas ausentes no ensino formal. Psicologia, Ciências Políticas e Econômicas, Direito, Criminologia e Arquitetura são algumas fontes de conhecimento úteis para a vida e ausentes do currículo. Nessa perspectiva, o autor se posiciona atestando que não se deve parar de ensinar os conteúdos obrigatórios, mas ampliá-los para o desenvolvimento de competências para a vida.

O nono capítulo, Começar pelas enquetes, inicia-se com o postulado que acompanha o autor ao longo da obra de que a escola atual não dá conta de preparar seus educandos para a vida que os espera fora das paredes da sala de aula. Dificuldade essa acentuada pelo distanciamento das Ciências Sociais e Humanas. Essas "lacunas" da escolarização, às quais Perrenoud faz menção, poderiam ser atenuadas se as competências e os conteúdos escolares se aproximassem mais das práticas sociais e da vida das pessoas.

A terceira parte da obra, Um reequilíbrio necessário, mas pouco provável, introduz o tema dos capítulos finais: o papel da escola perante questões de utilidade pública, como problemas ambientais, crises econômicas e vida no planeta. O décimo capítulo, É possível esclarecer as finalidades da escola, pontua que o aluno não vai à escola 
simplesmente por cumprimento de carga horária, mas sim em função de desenvolver recursos para enfrentar as situações de vida a partir de conhecimentos, competências, atitudes e valores.

Aqui entra uma pertinente indagação: “O que a escola deve fazer para preparar os jovens para a vida?” (p. 164). Perrenoud ressalta que as respostas são puramente complexas, uma vez que a escolaridade não é ponto de partida da vida do aluno, a qual requer muito mais que uma mera preparação para a fase adulta. Esse apontamento é acentuado pelo fato de o indivíduo estar em constante transformação, produto de um processo dinâmico que é a vida em todas as suas fases do desenvolvimento. Soma-se a tal o fato de a escolarização preparar o jovem até uma certa etapa de sua vida, e não para sua totalidade, visto que não é possível conceber com precisão o que esses sujeitos vivenciarão. Cada ser é singular no que diz respeito à sua história e condições de vida, o que contribui para a consistência da diversidade, concebendo esse sujeito singular em sua plena pluralidade.

Essa noção de coletivo requer a participação de outras instâncias para a formação integral do cidadão, como a educação familiar e religiosa, por exemplo. Dessa maneira, afirma-se que a educação não se dá unicamente entre paredes de uma sala de aula, mas sim em outros espaços, como a cantina, ou o pátio, onde não há supervisão direta do professor. A educação não formal também é espaço de construção de aprendizagem em preparação à vida. Perrenoud, por fim, evidencia que, perante a heterogeneidade de interesses e pontos de vista, o trabalho do professor se torna complexo e, muitas vezes, uma utopia.

As duas missões da escola, capítulo de número 11 da obra, reforça o papel da educação, abordando dois conflitos notórios acerca de interesses. Primeiramente, em relação ao nível. O autor endossa que os programas escolares são designados para alunos com rendimentos variáveis entre médio a bons, criticando o que ocorre com aqueles que apresentam dificuldade: quando começam a entender determinado assunto, o professor já avançou no conteúdo para cumprir seu planejamento.

Em um segundo momento, elencam-se conflitos em relação aos conteúdos. Aqui Perrenoud distingue os objetivos de alunos das classes média e alta - os quais buscam se preparar para uma formação continuada (especialização, mestrado, doutorado) - dos alunos de classes menos favorecidas - que objetivam, em sua maioria, uma preparação para acessar o mercado de trabalho. Perrenoud questiona, então: "Seria possível obter um consenso?" (p. 178). E pondera que muitos países vêm adotando a proposta de uma base comum que comungue dos mesmos objetivos enquanto currículo e conteúdos.

A ideia de base comum de conteúdos se afirma no capítulo 12, Não abalar as relações de força, quando o autor afirma que, para que haja uma igualdade, uma homogeneidade na organização prática da educação, é necessária a compreensão daquilo que é essencial, além do entendimento do seu papel no processo educativo. Conecta-o ao capítulo final da obra, Os impérios disciplinares, no qual elenca algumas disciplinas do currículo vistas como mais 
importantes - matemática, ciências, língua materna e estrangeira -, sobrepostas às que não assumem tal prestígio - aquelas que têm o espaço de uma ou de duas horas semanais no currículo e são caracterizadas pelo autor como "simbólicas" (p. 193).

O capítulo final do livro se intitula Uma conclusão um tanto provisória, e, como o próprio título indica, com muita propriedade, há uma instabilidade nítida entre o ensino de saberes ou o desenvolvimento de competências no ambiente escolar visto como uma preparação para a vida. $\mathrm{O}$ fazer docente levanta muitas hipóteses que se agregam à aprendizagem, favorecendo o aprimoramento de habilidades e competências dos educandos. No entanto, há muito por trás dos bastidores do palco que é a sala de aula. Há um currículo engessado que ultrapassa gerações, e, por mais que pequenas modificações sejam feitas, a estrutura se mantém inalterada. Indica-se a leitura da obra de Perrenoud a todos os profissionais ligados direta ou indiretamente à educação, bem como aqueles que nela percebem um caminho de mudança alicerçada sobre um rompimento de paradigmas ainda tão consolidados, mas que podem e devem ser repensados.

Recebido em: julho/2017

Aceito em: outubro/2017

Endereço para correspondência:

Av. Vítor Barreto, 2288 - Centro

92010-000 Canoas, RS, Brasil

<marina.mincato@lasalle.org.br> 